\title{
A Comparative Leadership Approach for Decolonising Educational Leadership in Africa: The Case of Two Headteachers in the Democratic Republic of Congo and in England
}

\author{
Jean Pierre Elonga Mboyo \\ Teesside University, Middlesbrough, United Kingdom
}

\begin{tabular}{lr}
\hline Abstract & Article Info \\
\hline This research compares the accounts of two experienced urban & Article History: \\
primary headteachers based in Kinshasa (Democratic Republic of & Received \\
the Congo-DRC) with two others based in Sheffield/Doncaster & October 20, 2020 \\
(England), in order to make sense of their leadership pathways, & Accepted \\
challenges and approaches. Engaging these school leaders through & December 15, 2020 \\
leadership conversations within a narrative research tradition, the & \\
extracted data were analysed thematically and using & \\
phenomenological interpretive analysis. Despite differences in their & \\
stories of actions regarding the researched themes, a comparative & \\
theory of context(s) emergences which adds to how school leaders & \\
can think and act locally and globally and, in the case of African & Keywords: \\
school leaders, decolonise their practice of any dominant & Comparative \\
normativity as they define what is best for their schools. This & leadership; DRC; \\
involved headteachers being attuned to their personal, professional & England; Scope; \\
and comparative dimensions of 'the gospel according to the & Urban Schools; \\
headteacher' metaphor and ultimately deploying their connect & Values \\
comparative core values to rise above the subjective or objective & \\
scope of one's context in order to bring about change that primarily & \\
benefits children. &
\end{tabular}




\section{Cited as:}

Elonga Mboyo, J.P (2021). A comparative leadership approach for decolonising educational leadership in Africa: The case of two headteachers in the Democratic Republic of Congo and in England. Research in Educational Administration \& Leadership, 6(3), 586-623. DOI: 10.30828/real/2021.3.3

\section{Introduction}

\section{A Call to Action}

Ten years ago, Townsend (2010) urged scholars in the field of educational leadership to help headteachers and other school leaders to think and act locally and globally. Despite an increase in nationalistic discourse, particularly in the political arena, the common demographic, technological, environmental, cultural, wealth and health concerns that societies across the world were going through that prompted such a call remain pertinent. Dimmock (2012, p.202) also notes some cross-context organisational issues such as:

Greater parental power and influence on schooling, more specialisation of school curricula, broader diversification of school types, continuing decentralisation of responsibilities to school-site leaders, increased acknowledgement of teacher professional development and professional learning communities, and of leader preparation and development...

This second-linked article uses data from a comparative study carried out between 2012-2016 to exemplify how headteachers can think and act locally and globally and, arguably in the case of African school leaders, decolonise educational leadership practice. However, the way that not only ontologies, epistemologies and cultures have been compartmentalised, as discussed in the first-linked article, but also the way the field of educational leadership has been fragmented militate against any attempt to develop theories and practices that deconstruct 
various normative enclaves without compromising evolving contextual uniqueness and identities.

\section{Compartmentalised Field}

Townsend's call cannot, in my view, fully blossom within compartmentalised, bounded and essentialist theoretical approaches to thinking and acting as a school leader in both northern and southern hemispheres. For example, the territorial leadership approach which focusses exclusively on African leadership and management practices (Zoogah \& Nkomo, 2013), as previously discussed in the first-linked article, is testament to the compartmentalisation of context, research and practice. Despite the urgency to think and act locally and globally and rise beyond (think through and/ or reframe) models of leadership, knowledge domains, the western educational leadership discourses have been described as partial (Bush, 2011), singular (Ribbins \& Gunter 2002), and fragmented (Eacott, 2015). This is pertinent reminder to rethink the field, particularly in its (international) comparative education, enmeshed in diversity that requires inclusion, or rather, reframing of local and global realities and approaches so that successful school leaders that 'embody most or all [leadership] approaches in their work' (Bush \& Glover, 2014, p.565) think and act from a professional mindset that is reflective of the reality of our contexts.

\section{State of Play in Comparative Educational Leadership Theorising}

Although theory development, particularly of fragmented approaches, has kept a pace with increasing interest in school leadership in the last two or three decades (Bush \& Glover, 2014), the theoretical basis of its comparative branch is still lagging. Without discounting the multiple published and ongoing comparative research projects, some pioneering literature-based attempts to theorise on 
multicultural comparative school leadership (Collard, 2007; Dimmock $\&$ Walker, 2000) have lacked in their empirical basis. To bridge that gap and bring the global to our local contexts and vice versa, Day and Gurr's (2014) notable empirically-based contribution in international leadership literature rather contains individual approaches of headteachers across the world assembled in one book publication without reflecting on their wider comparative significance (Schweisfurth, 2001). Put differently, it is not clear how local school leadership practices, in increasingly diverse contexts, offer a theoretical and professional basis for (global and local) school leadership. This study is unique in that it compares the leadership practices from an African local context with a European one in order to propose an empirically-based global/local comparative theory and practice of school leadership. It is particularly pertinent as it exemplifies how Africans are reimaginig how to decolonise school leadership in a way that opens them up to global perspectives without compromising and jeopardising its own African (emancipatory) identity.

\section{Framing the research}

Without revisiting arguments already outlined in the first linked article, this study responds to Townsend's (2010) call by framing the research from a Comparative Research Concept (CRC). As already argued above, some comparative theories of context have been advanced (Collard, 2007; Dimmock \& Walker, 2000). They, however, lack the emparical basis. The CRC theoretical framework for this study is, therefore, unique in that it does not impose theoretical assumptions that would determine the development of an empirically-based comparative theory of context. On the contrary, CRC only advances underpinning theoretical safeguards to engage in cross-context 
comparative educational leadership research that would result into data-driven (grounded) theory (ies) of context. The underpinning theoretical safeguards, arguably, involve honouring 'localised thinking yet [moving] beyond it to see multiple possibilities, multiple influences and multiple perspectives' (Sackey \& Mitchel, 2002, p.909). Put differently, decolonising (African) leadership practices from both western oppressive normative practices and 'locally engineered tyrannies' (Elonga Mboyo, 2018, p.122) 'brought about by, [for example], a lifetime of immersion in one [own] culture' (Lumby \& Heystek, 2011, p.7) that prevent us from seeing things afresh involves recognising 'both the differences and interconnectedness of the world and $[. .$.$] challenge accultured limitations' (p.7).$

In this mindset, educational leadership researchers and practitioners strive to ontologically, epistemologically and culturally emancipate the elements that constitutes their local school contexts while configuring them within broader shared and/ or differing global meanings. Such school leaders are able to look 'comprehensively across leadership frameworks or experiences, cultures [my italics] (Reed \& Swaminathan, 2015, p.1120) and adapt the art and science of leadership in their respective contexts of leadership. The reader is, therefore, invited to bear this, and the ontological, epistemological and cultural argument for CRC made in the first-linked article, in mind whenever reference is made to 'comparative leadership' hereafter.

\section{Context and Methodology}

This study is focussed on school leadership experiences of two urban primary head teachers based in Sheffield/Doncaster within the Sheffield City Region (SCR) in England and two others based in Kinshasa in the Democratic Republic of Congo (DRC). The contrasts in 
the experiences of the two sets of head teachers (Bafote and Lokuli for DRC and Fiona and Donald for England) and the contexts within which their schools are located could be described, as do Brock and Alexiadou (2013, p.131) when referring to educational landscape in Sub-Saharan Africa, as unparalleled. Two examples relating to budget and staff competency suffice to illustrate the differences. While Bafote's school of over 740 fee-paying children ran with an estimated budget of an equivalent of seventy thousand British pounds, Fiona had, at her disposal, over one million Pounds for 320 pupils. Only 7\% of Bafote's teaching staff had received a university education while the rest were secondary school leavers. Fiona's staff had a university qualification beside/alongside the professional training as teachers. Despite the few contrasts among many others, there were some converging features that are worth noting about the two sets of heads and their respective settings. The heads' schools were situated in urban contexts serving people from different cultural, linguistic, national and ethnic backgrounds; they are experienced and happen to be all Catholics three of whom leading Catholic schools.

To capture the experiences of the above head teachers in two contrasting settings yet similar in terms of diversity, the research employed 'leadership conversations' (Riessman, 2008) within narrative traditions (Bold, 2012) as a way of extracting data and therefore subscribing to the CRC as described in the first linked article. After a convenience sampling of participants on the basis of the location of their schools being in an urban city and being experienced, between 2-3 conversations for each participant lasting between 40-55 minutes were recorded, transcribed, translated and analysed in two phases. Goodson (2013) argues that stories of actions should be understood within theories of context. The first level of analysis, therefore, thematically interprets and contrasts accounts of school 
leaders' journeys/pathways to school leadership, their leadership challenges, how they respond to those challenges and their views about good school leader. The second level of analysis, inspired by Vandermause et al.'s (2014) interpretive phenomenological analysis to work out ontological underpinning structure behind data themes, sought to understand and/ or develop a theory (theories) of contexts from the thematic stories of actions. A combination of lengthy excerpts and brief ones was used to represent the themes and concepts abstracted.

\section{Findings and Discussion}

As shown in Table 1, the first level of analysis which thematically sought to understand various narrative stories of actions returned notable contrasting features between the DRC and English head teachers in response to research questions focusing on pathways to leadership, leadership challenges and actions. 
Table 1.

Data theme summary

\begin{tabular}{|c|c|c|}
\hline DRC data themes & $\begin{array}{c}\text { Research objectives/ } \\
\text { questions }\end{array}$ & English data themes \\
\hline $\begin{array}{l}\text { Innate vocation, no } \\
\text { formal training, on the } \\
\text { job-learning }\end{array}$ & $\begin{array}{c}\text { How are journeys/pathways } \\
\text { to school leadership } \\
\text { described? }\end{array}$ & $\begin{array}{l}\text { Exploratory, formal training } \\
\text { and on-the-job learning }\end{array}$ \\
\hline $\begin{array}{l}\text { Societal moral decay, } \\
\text { poor working/life } \\
\text { conditions, staff/students' } \\
\text { educational competencies }\end{array}$ & $\begin{array}{l}\text { What are the leadership } \\
\text { challenges that } \\
\text { DRC/England head teachers } \\
\text { face as they go about their } \\
\text { work? }\end{array}$ & $\begin{array}{l}\text { Cross and intra-schools social, } \\
\text { curriculum and professional } \\
\text { dysfunctionalities; and the } \\
\text { functionality of extreme } \\
\text { practices }\end{array}$ \\
\hline $\begin{array}{l}\text { Administration, } \\
\text { pedagogy and finance; } \\
\text { Humanistic leadership: } \\
\text { Ubuntu; Collegial; } \\
\text { Servant. }\end{array}$ & $\begin{array}{l}\text { How do they go about } \\
\text { responding to those } \\
\text { challenges? } \\
\text { Emerging eclectic/ } \\
\text { comparative leadership } \\
\text { theory of context as } \\
\text { headteachers in both settings } \\
\text { worked through an apparent } \\
\text { adjectival array of leadrship } \\
\text { constructs. }\end{array}$ & $\begin{array}{l}\text { Self-improving; Egalitarian; } \\
\text { systemic; dialogical; } \\
\text { Instructional; distributive; } \\
\text { collaborative; humanistic; } \\
\text { Middle-ground leadership }\end{array}$ \\
\hline
\end{tabular}




\section{Pathways}

The contrasts between the DRC and English headteachers on this subject were striking. For the DRC headteachers, teaching and leadership were innate qualities as summed up by the following extracts:

I had a soft spot for teaching (j'ai un faible pour l'enseignement)]; I loved my teachers who initially spoke very well. It is they who have led me to love this job. Then gradually I did my studies in applied education, I was hired right after my studies (Bafote)

Lokuli put it more vividly with the following:

For me it is an easy profession, I [easily] find my way through, headship is an easy profession for me, and it was in my blood ...' (Lokuli)

In the absence of professional and academic programmes to develop school leadership, becoming a head teacher is the result of on-the-job learning across (rigourous or fast-tracked) performance-based stages that add to the above claimed innate nature of leadership:

You begin as a teacher before you are promoted to exercise the functions of a sur-école (surnuméraire, meaning an additional number), deputy head and then head. You must also have passed through all the stages of primary school to allow you to manage them. I started as a teacher for 6 years, after which I was promoted as deputy head and 5 years later, I became head. There is a mechanism, although I didn't go through it all. (Lokuli)

By contrast, the English counterparts' narratives portray school leadership as the result of exploration and discovery as opposed to an innate attribute.

When I became a teacher, I didn't think I'm going to become a head teacher. I wanted to see what this world of teaching was going to be like really...then you begin to think maybe I could do better; I could give more, and I can only give more if I'm in a higher position. (Fiona) 
This exploration happened within a life-long career in education and sometimes outside of it:

I left teaching altogether and worked for an insurance company but that lasted for two years then the market crashed and returned to teaching and worked my way up to becoming a headteacher. Donald

The uncertainty around the need for professional qualification for headship reflects the changing direction in the political landscape in the United Kingdom:

They made it compulsory to have national professional qualification for headship, which is run from the national college. You can get a deputy leadership qualification through there as well. They did it at one point and then they scrapped it but I think they [the government] are bringing it back again. (Fiona)

Despite the changes, Fiona asserted the importance of on-the-job learning when referring to a situation with her former head early on in her career and therefore privileging the combination of formal training and on-the-job learning rather than mainting a false dichotomy between the two:

So he [the head] really left the running of the school to me [deputy] while he went in the cellar to smoke a pipe, or did whatever he did. So I actually did five years of getting to know what the school was about, running finances, running the classes as well and most of all, the really, that even though you are a teacher, if you get the parents on side you can do anything' (Fiona).

The differences in these head teachers' pathways to leadership are stark but they are not absolute and that while these dominant contrasting features are pertinent, they only give us an indication within the limits of the small-scale nature of the study.

Challenges: The DRC school is primarily portrayed as representative of the (dis) values of its overall national environment: 
My school is the Congo in miniature. Everything you see there [in terms of moral, economic, and educational challenges] is happening here. (Bafote)

The societal challenge of poverty is then reported to have permeated all layers of society, including schools. This manifests itself in the scarcity of resources:

Because a teacher is a perpetual learner, I tell the authorities that I need this..., give me the means/resources. You do not get those means/resources... and when you have a fault due to lack of resources you are blamed for it. (Bafote)

Within an overall environment of poverty seen through poorly resourced schools (De Hert et al., 2012; Shapiro \& Tambashe, 2001), poorly paid professionals are reported to engage in corrupt practices:

You will go in some state schools: when a teacher arrives, he puts a moneycollecting basket in front and the students give what they can and the teacher keeps a list of contributors for recompense when awarding marks. He takes a notebook and asks a student to copy something on the board and at the end of the year the child passes to the next class with an empty head having learnt nothing. (Bafote)

For various reasons, including poor resources as mentioned above, the educational competencies of pupils, particularly literacy skills as also reported elsewhere (UNESCO, 2012), were a major concern:

The big problem we face at the moment is with reading. Many students cannot read. (Bafote)

Bafote also made reference to teacher incompetence illustrated by the deficiencies of a trainee teacher:

We had a trainee teacher who was teaching the wrong things, imparting the wrong kind of knowledge that even the pupils disagreed [student teacher was teaching the conjugation of the verb 'to be']. (Bafote)

By contrast, the challenges the English counterparts articulated were more of a systemic nature. Two key ideas that stood out from 
their narratives pointed to cross and intra-schools social, curriculum and professional dysfunctionalities and school leadership extremes (policy and people centred) encountered in the course of their careers. Social fractures depicting the urban nature of setting in the two sampled schools in England and impacting on the intra-school cohesion were summarised in the following extract:

It was really weird because we started getting Polish children into the school and I don't know the background and history, but travellers don't like Polish people. And this Brendan's mum said once in a meeting: I'm just fed up with these Polish coming over here and getting all the jobs. I said, actually the Polish parents we've got are electricians and they are really skilled people and to be perfectly honest if nobody is fitting the job why shouldn't they work? I said 'why don't you train to be an electrician?' (Fiona)

The symptoms of cross-school fractures were evident. Fiona noted with the following as she observed how high educational standards and engagement with tasks diminish as children move from primary to secondary schools:

You do so much with them and the moment they move to secondary, it just evaporates. We had a year 13 (secondary) and year 2 from our primary) link programme as part of the buddying process. The year 13 from $x$ secondary went on a trip with our year $2 s$ and at the end of the process they were meant to record thoughts. We handed them with an A3 sheet, and our children go on with their writing straight away whereas the year 13 looked on and first asked; 'what? You expect us to write on that and fill it up with information? (Fiona)

The intra-school professional dysfunctional fractures that concerned the participants were voiced as follows:

...also, I have been in situations where there have been little enclaves of staff talking in their little spaces and I'm thinking I can't stand that (Fiona)

As well as the dysfunctionality between various educational entities, Donald noted the functionality of what he deplored as extreme 
leadership approaches. On the one hand, he described a top-down approach of the head teacher under whom he had worked and which, for Donald, was problematic:

It was meticulously planned, and policies were the policies and they were tinkered with but they were never massively overhauled because once she decided that's how we've got to do it, that's how we were going to do it. Every time there was an issue, it was referred to the policy: handwriting for example, everybody had to write your crossbar had to be at the right height, if you had two letters with a crossbar together, you use one crossbar. If you had fractions and you were in the infants, you had larger squares...so you knew exactly ...thus affected everything. If you had a policy, you had a policy. (Donald)

In another school he went on to work, Donald noted a different collegial and post-modern leadership approaches (Bush, 2011) he favoured but still noted the problematic extreme it represented:

It was absolutely the opposite. It was, you know, where is the policy? Do we have a policy on this? It was a very small school; staff meetings were very good, creative and loud sometimes. I loved the passion of the teachers in this second primary school. You didn't have the passion in the first school. It didn't feel like your voice was being particularly heard. (Donald)

Overall, these thematic findings for the first two research objectives uncover new contrasting leadership pathways and challenges as well as reinforce literature-based claims about, for example, innate and learnt leadership traits (Northouse, 2016), poorly trained staff and school leaders as well as the uncertainty for optional or compulsory leadership training (Bush, 2013; Higham et al., 2015; Mokonzi, 2010; Zame et al., 2008) echoeing the overall need to tackle an ongoing global shortage of school leaders (Chapman, 2005; MacBeath, 2011). The foregoing findings combined with issues of poverty, pupils' poor outcomes, and other intra and cross-schools systemic challenges bring to the fore Jha's (2007) intricate external and internal barriers to 
learning and schooling that affect both students and staff. It is understandble that, as a reader, you may be left with a sense that these themes could have been further discussed and framed differently. However, this study's primary purpose for capturing the essence of participants' narratives on their leadership pathways and challenges was instead to understand how these headteachers responded to these challenges as presentd and discussed below.

School leadership actions as a response to challenges. DRC participants were first of all mindful of the official policy that calls on all head teachers to develop their leadership anchored on three constructs mainly administrative which is akin to managerial and bureaucratic leadership advanced both in the West and Africa (Beugré \& Offodile, 2001; Bush, 2011), pedagogical which focuses on teaching and learning or instructional leadership, and financial leadership:

All the head teachers are called to be good administrators, develop good pedagogical practices and manage well the finances of the school. If you apply these [meaning administration, pedagogy and finance], your school will be the best.

In the face of extreme poverty affecting all stakeholders particularly teachers, the DRC participants were prepared to stray from orthodoxy of the above prescripte ladeship approachs and take the initiative to act with humanism or Ubuntu leadership which is extensively discussed elsewhere (Elonga Mboyo, 2019).

I do my work with authority but also with humanism. By humanism I mean I understand the discomfort of others. There are times when a teacher comes to me and says: look Mr head teacher, I am in need of money to deal with this emergency, then I say take this much [ussually from the school's fund], you will reimburse at the end of the month. When I respond like this, it injects a feeling of friendship and humanity and it makes them accept you as a leader beause you understand their situation. (Bafote) 
The foregoing sample of leadership approaches to be seen against Bafote's admission that '...to update our [their] practices, we [they] also inform oursleves [themselves] using what is being done in other places/lands' in order to grasp the fundamental drive to work across various leadership frameworks and incorporate non-local ideas (hence, be comparative) and hopefully be effective when leading urban schools.

On their part, the English headteachers focused, among other approaches (see Table 1) on mending internal and external fractures between different entities as well as finding the middle ground between extreme practices of leadership. The concept of 'bridger' (Bruce-Golding, 2019) captures the role of these headteachers who sought to be inclusive by bringing all into an heterogenous cohesive whole:

Our school governing body is made up of members who are varied: we've got some strong church goers, a person who is a strong Muslim active but aware of this being a Catholic school where his children go, aware of the ethos, but it brings a very interesting dimension to the discussions because he is trying to broaden what we are doing without diluting it. (Donald)

The above apparant democratic or participative approach to school leadership, that also characterised Fiona's approach, was coloured by elements of rationality that is associated with managerial leadership while also deploying other skills in order to navigate the complexity of managing human beings as suggested by the extract below:

So, when I came for my first headship, I said I need a bit of the management side from that head and a lot of that people skills from that head. I could do with the consistency in that... (Donald)

The reference to school leaders' people's skills became more apparant when Fiona advocated for the need for what could arguabky termed 
as emotional leadership, to deal with pupils' emotional fractures in her school and when they move on to scecondary school:

...the psychologist I employ allows the staff to observe her so that they can see strategies that work with her and she then gives them advice... She gives them [teachers] information that they can work on over a period of time. I think if you have a professional body that's working in and around the school and it's like on tap, I think that would alleviate many issues high schools. (Fiona)

When consumed by the administrative role, they were able to switch and adopt other approches that they felt were also needed and the case of instructional leadership, among others, illustrates their ability to work across frameworks which in essence is a comparative exercise:

...the last two months I have been dealing with pay policy with all these changes, and I just think why do I want to do that, I actually want to be in the classroom and look at teaching and learning. (Fiona)

The teaching and learning is seen as the primary mission that the head teacher and senior staff must model for the othr staff members to emulate:

...the thing for me is that I can teach, I can go into a classroom tomorrow and I can get the very best out of children because if you love teaching in the first place you never lose sight of why you were there in the first place. So as long as they know that you can do what you are asking them and bring in mentoring and coaching and it stems from the head and your senior leaders. (Fiona)

The individual strands of leadership approaches adopted by the English and DRC headteachers in this study are arguably different and similar at the same time. Limited space precludes an elaborate discussion about the complexity of each approach as illustrated elsewhere in the case of an arguably local african reimagined Ubuntu leadership in the DRC (Elonga Mboyo, 2019). What is strikingly of interest here is that both sets of head teachers displayed an eclectic style of leadership which is essentially comparative by virtue of its 
attempt to look across different leadership approaches and settle for this or that approach at a given time and space. The pertinent issue of exploration for this special issue, therefore, is to establish how these DRC head teachers and others in Africa (Maringe and Moletsane, 2015) can decolonise educational leadership while working comparatively across a wide range of local and non-local leadership frameworks.

The second phase of analysis, therefore, sought to identify overlapping patterns in the above thematised analysis and other narratives, in order to establish the underlying principles behind, in this case, eclectic/comparative leadership (Vandermause et al., 2014). From the stories of actions about pathways to leadership, leadership challenges and eclectic leadership approaches, the second analytical phase aimed to develop an underlying (northern and southern hemespehere's) theory of context(s). This would hopefully explain how the sampled school leaders navigated various power structures in order to think and act locally and globally and, arguably, in the case of DRC school leaders, decolonise educational leadership practice. In so doing, it became clear that 'scope', leadership metaphors and leadership values are the conceptual elements that contributed immensely to the comparative leadership behaviours they exhibited. The remainder of this article will attempt to construct a data-driven and at the same time literature-informed complex theory of context underpinned by constructs such as scope, leaders' identity layering metaphor and values that enabled them to comparatively look across leadership frameworks and decolonise educational leadership in the DRC. 


\section{Scope}

There was a consistent theme running from pathways to headship, through the framing of leadership challenges to good leadership behaviours. It is called 'scope'. This concept is too crucial to over-philosophise. 'Scope' is quite simply freedom or 'room for manoeuvre' as well as the constrains that these sets of heads did or did not have in their respective environments and what they were able to do as a result of it. 'Scope' is neither agency nor structure although both are essential components that can be polarised, overcome, bracketed, flattened, stratified, relationalised... depending on the nature of practitioners' actions rather than adhere to a researcher's predetermined ontological stance. As shall be explored next, the engagement with 'scope' is frought with power dynamics, deeper questions about head teachers' (cultural, religious...) identities and the values spurring them on to be comparative and decolonise educational leadership despite or because of an enabling or constraining nature of scope.

This study's data point to a relatively contrasting ontological environment that is either more restrictive (in the case of the DRC) or more open (in the case of England). Restrictive scope is more centralised, top-down and vertical (more objective and less subjective), while open scope is more decentralised and horizontal (less objective and more subjective). When scope is vertical, it is objective and like Hooge et al.'s (2012) vertical accountability which seeks to comply with normative realities, laws and regulations. Horizontal scope, by contrast, depicts the subjective nature of room for manoeuvre and similar to Hooge et al.'s (2012) horizontal accountability which take account of the input of students, parents, communities, and various other stakeholders. 
It can initially be hypothesised (see Table 2), therefore, that the less rigid/pervasive or more compressed is the vertical accountability (scope), the more extensive becomes the horizontal accountability and hence giving headteachers more room for manoeuvre and be more comparative. In the same vein, the more rigid, expanding and pervasive the vertical accountability (scope), the less comparative the school leadership, even though that was negated here by DRC heads who circumvent the system. As shall be shown in subsequent sections, these ontologically predetermined assumptions about the two contexts can be overcome by the agency of more comparative school leaders. Table 2.

Increased/Decreased Vertical and Horizontal Scope

\begin{tabular}{ccc}
$\begin{array}{c}\text { Increased horizontal scope } \\
\text { (more room to be comparative) }\end{array}$ & $\begin{array}{c}\text { Decreased } \\
\text { vertical scope }\end{array}$ & $\begin{array}{c}\text { Increased horizontal scope } \\
\text { (more room to be comparative) }\end{array}$ \\
\hline $\begin{array}{c}\text { Decreased Horizontal } \\
\text { scope; less } \\
\text { comparative }\end{array}$ & $\begin{array}{c}\text { Increased vertical scope } \\
\text { (expanded/rigid) }\end{array}$ & $\begin{array}{c}\text { Decreased Horizontal scope; } \\
\text { less comparative }\end{array}$ \\
\hline
\end{tabular}

\section{More Objective/Less Subjective Scope - More Centralised (DRC)}

The evidence here is consistent with research from Greece (Kaparou, 2013; Kaparou \& Bush, 2016), West Africa (Bush \& Glover, 2016) and Rwanda (Kambanda, 2013), which prompted Bush and Glover (2014, p.565) to suggest that African countries and Eastern and Southern European contexts were more centralised, in the sense that the 'principal's role often remains that of implementing external imperatives with little scope for local initiatives'.

The two DRC primary school heads who were part of this study appear to imply that the environment was ontologically objective and, 
therefore, subjectively restrictive. This can be traced back to the 'pathways to headship' section, where the sense of headship was perceived to be innate and seemingly aspiring to maintain an established order. Besides, the framed leadership challenges lent themselves to direct policies that would only perpetuate an existing order rather than change it. Similarly, when discharging their leadership responsibilities, Bafote, for example, operated within two spaces (the religious space to which the school is affiliated and the state space), echoing views that pointed to the existence of objective structures that defined school leadership. His religious space had what he called a 'disposition'. However admirable the disposition may be, it was what was expected of him and of all the heads who had worked in that school, as the following comment shows:

They [all head teachers at Baf] came from elsewhere and as soon as they arrive [at Baf] ... they find a certain disposition. Bafote

When referring to the state's space, both Bafote and Lokuli's converging accounts were quite revealing. For them, good school leadership consisted of 'paying attention to the administration, pedagogy and finance ...' of the school as prescribed in the official documents and believed to be the formula for success:

If you apply these [meaning administration, pedagogy and finance], your school will be the best. Bafote

As already stated, this is in line with reports of highly bureaucratic, mechanistic and autocratic leadership in Africa (Beugré, 1998; Blunt \& Jones, 1997; Jones et al., 1996; Kiggundu et al., 1983). What is intriguing, however, is that Bafote said 'your school will be the best' instead of 'you will be the best headteacher'. This confirms his apparent oscillation between his school living up to what was required of it to be 'the best' (in administration, pedagogy and finance) in the eyes of 
inspectors, for example, and his comparative authoring of, an arguably decolonising, school leadership (through humanism that led to eclecticism and comparative approaches). The humanism and other leadership approached required, in part, more agency in the way of circumvention and openness to 'knowledge from other lands' showing that comparative leadership is a disruptive practice leading to new practices, through interrogation of orthodoxy (Eacott, 2013; Thomson, 2010) to gain more scope as shall be discussed in detailed later.

\section{Less Objective/More Subjective - More Decentralised (England)}

Having more room for manoeuvre is one thing, using it as a springboard for substantial change is another. Instead of maintaining the status quo, Fiona and Donald expressed their drive to explore and change; they framed their challenges in such a way that overcoming them would require systemic change. Unlike Bafote, who had to circumvent to be more creative, Fiona, for example, used the power she had to take various initiatives as she saw fit, as the following extract capturing the experience of being appointed a confederation head shows:

They [the diocese] couldn't tell what it was that they wanted me to do. I said what do you want it to look like in a year's time, three years' time and they couldn't tell me. And I said, are you saying to me that I am to create this federation and strategically manage it and put the layers of staffing in that I think is required? And they said yes. I said and if it goes all wrong, I am to blame? [...] I said, well I like a challenge. (Fiona)

All these elements point to more subjective, decentralised and less rigid scope.

However, it is argued that the educational landscape in England has been subject to constant policy change (Glatter, 2012). A view that is confirmed by Donald in the following extract: 
Things are constantly changing, and they have never stopped changing. (Donald)

It may, therefore, be argued that the less rigid and autonomous rhetoric characterising Fiona and Donald's narratives is, in fact, an echo of the autonomy they would assume to implement continuous and constraining government policy change (Glatter, 2012; Hammersley, 2015), especially in aligning public sector bodies, such as schools, to the private sector's principles of choice, accountability etc. (Gunter \& Fitzgerald, 2008). Simkins (2003, p.215), however, problematises the term 'autonomy' and sees in it 'a degree of freedom which few if any organisations in the modern world can achieve' absolutely and that scope, both in its vertical and horizontal dimensions, is a dynamic concept.

It is, therefore, argued here that, in comparison to the experiences of Bafote and Lokuli, Fiona and Donald acted within an environment with a greater degree of scope and autonomy which is consistent with previous reports about the educational environment in England (Bush \& Glover, 2014; Hooge et al., 2012; Kaparou \& Bush, 2016).

\section{From Scope to Action: Exploring Missing Links}

Having a limiting or open scope is one thing but taking action thanks to or despite the nature of one's scope is another that conveys (comparatively decolonising) agency. More autonomy and deregulation, in the case of England, can imply more regulation (Glatter, 2012; Hammersley, 2015) that some headteacher have attempted to circumvent (De Angelis et al., 2007; Michalak, 2012) and more objective scope in the DRC does not automatically imply conformity as professionals have agency and in a broken system where communication is hard, if not non-existent, some heads may not even 
be aware of government regulations; hence, headteachers' agency becomes the norm. The centrality of headteachers in the future direction of the school community is captured by Donald who suggested that leading schools is the gospel according to the headteacher'. Whether the system is centralised or decentralised, it is about how and why one (the head and the whole school) responds to the challenges. In analysing the different layers embedded in the above metaphor, one is struck by, not only the similarity in the layered way that these sets of headteachers operated but also the values that propelled them into action.

\section{Metaphor: 'It's the Gospel According to the Head Teacher'}

Educational leadership and organisational theories have a variety of metaphors too (Heck \& Hallinger, 2005; Morgan, 2006). The DRC head teachers, in this study, did not explicitly advance any metaphor to make sense of their leadership actions, unlike Donald who summarised his experience as being about:

The gospel according to the head teacher. (Donald)

The above metaphor could be taken to signify the crucial role head teachers play in the success of their schools (Hallinger, 2003; Hallinger \& Heck, 1996; Hargreaves, 2003; Leithwood et al., 1994; Southworth, 2003). It exemplifies, as shall be discussed shortly that being an effective school leader is about navigating through a multi-layered response repertoire that adds further complexity to traditional normative and fragmented doxas about successful school leadership. When theorising comparative educational leadership, Dimmock and Walker (2000), for example, have offered a multi-dimensional approach to cultures (national, regional, local community, system level, school boundary and organisational cultures) that head teachers in multicultural settings can engage with. However useful Dimmock 
and Walker's analysis is, it is unlikely that headteachers would engage in such an elaborate analysis of cultural contexts in the immediacy of practice. It is, therefore, essential to grasp head teachers' self-styled way of sifting through complex layers of cultural, ontological and epistemological diversity.

The above metaphor is therefore a practice-based entry point into head teachers' stepped identities leading to a point when they define themselves as agents that will overcome any barrier and look comparatively across an array of frameworks for the good of the children under their care. Initially, Donald gave the metaphor a double meaning: the literal and the professional, although, on the basis of their narratives, I advanced a third meaning - the comparative which all together is reminiscent of Epitropaki et al.'s (2017) the personal, relational and collective selves of leaders' identity formation.

\section{Literal Meaning}

In its literal sense, the above metaphor is manifested through personal internalised convictions based on one's historical, cultural and religious, among others, trajectory. Bafote and Lokuli spoke of their experiences growing up in the Belgian Congo as follows:

'The Belgians taught us to work with rigour and deliver success and I expect that from my staff and children under my care'. (Bafote)

Fiona and Donald made reference to their Irish roots as having shaped their personal worldviews around race, wealth, poverty and other issues that provided into the way they operated.

'I came from a poor home but we were taught to work hard so I always give everyone a chance. I don't discriminate'. (Fiona)

While this stock of experiences can arguably be valuable in shaping leadership character (Schuttloffel, 2013) and developing the personal values/vision needed for problem solving, organisational 
learning, especially in diverse contexts and at a time of rapid change (Hallinger \& Heck, 2002), these personal beliefs '...may present a serious barrier...' (Reed, 2008, p.221) particularly for those who have internalised discriminatory views along the lines of race, sex, religion, ethnic origin etc.

\section{Professional/Organisational Meaning}

Donald's explanation of the meaning of metaphor at the 'professional' level amounted to describing more or less the crucial role that a head teacher plays in mediating organisational mission or culture (Dimmock \& Walker, 2000; Hallinger and Heck, 2002) that may or may not correspond with the literal meaning of the metaphor. Below is Donald's response to the clash of values after a school fight, that illustrate this clearly:

...So this was our first test of the gospel according to me as head teacher, to us as governors. Because the school governors set the strategic boundaries and as a church school, I said we cannot put those things in clearly and give them some sort of a reference and the other element was forgiveness. We do expect children to forgive. I said this is my interpretation of the gospel and I want your backing and it worked well. Gospel messages are quite simple and clear but just very difficult to follow. (Donald)

The religious and moral case that could be made to opt for forgiveness rather than retribution (or being punitive) is not being disputed here. The point, however, is that, in terms of the scope that heads in this study narrated, the established (catholic) order became the norm. '...her [referring to a headteacher under whom he worked] way became the HMI's way' (Donald) and 'if you apply these (meaning administration, pedagogy and finance as prescribed by the state), your school will be the best' (Bafote) are indications of how school leadership was framed in line with prescriptive organisational/establishment goals. 


\section{The Comparative Dimension}

'Leaders are expected to ground their activities in clear personal and professional values' (Bush, 2011, p.6). The foregoing literal and professional meanings of this metaphor are ways in which these four leaders drew inspiration from their personal and professional (cultural, ontological, epistemological...) selves that would have been shaped by their personal trajectories and professional affiliations. The comparative self (or dimension of this metaphor) is a subversive self. Although subversion can be negatively interpreted, its value is also known to enable head teachers 'to engage in a certain amount of deviant behaviour and express their desired identities within a role without risking too much role sanction' (Wang, 2018, p.542).

We turned certain things on their heads... (Fiona)

...This is the timetable that inspectors get to see when they come. It's in line with what they expect to see but my teachers are operating from a different timetable and teaching other subjects not prescribed because we know what is good for our children to excel in this world. (Bafote)

Rising beyond the (local) literal/personal and organisational values/knowledge involves creativity when filtering insights, research knowledge and leadership practices, as this representative extract illustrates:

...we update knowledge according to what is being done in other places/lands; ... and we are always on the lookout for new ideas whether on the bus or when listening to the radio...; I ask my teachers to research and share any new ideas they may have come across. (Bafote)

They take that risk of, for example, 'turning things on their heads' and having unofficial timetable as shown in the extracts below, to arguably 'seek the good of the pupil' (Hammersley, 2015). This approach to 
leadership can lead to engage with a whole array of leadership behaviours (hence, comparative) that are deemed appropriate in a given time and space. The already published Ubuntu strand of leadership emerging from this research (Elonga Mboyo, 2019) is just one example among many other possible eclectic approaches that could be explored separately in future research projects. What is the focus here is the emergence of an empirically inspired theoretical template for comparative leadership that school leaders, especially those in Africa as this study reveals, un/knowingly engage in when eclectically leading (and decolonising) leadership in their diverse settings.

Successful school leaders possess certain core values: willingness to take risk, academic optimism, emotional resilience, hope and moral purpose (Day et al., 2011). The same can be said of comparative school leaders in this study. While headteachers operating at the literal/personal level of the metaphor privilege their personal convictions and values and those at professional level champion what is good for the organisation, comparative school leaders in this study are, arguably, motivated by 'what is good for the students/pupils' even if it means going against personal and organisational values. Headteachers in this study showed the following pattern of values: risk taking, inclusivity, integrity (derived from honesty, transparency, humble learning, trustworthiness and tolerance) and success-mindedness (both academic and human).

Limited space precludes an extensive discussion here about the complexities in deploying these cores values as experienced by the headteachers in this study. Suffice to note that these comparative school leaders who were prepared to circumvent were primarily driven by the sense of risk taking. They took the risk to, for example, 
have parallel timetables (in the case of Bafote) or turn things on their heads (as stated by Fiona). Contrary to thinking and acting in a compartmentalised way, these headteachers unanimously underlined the need to be inclusive in a racially, culturally, epistemologically diverse world. This social justice core value was exemplified by, for example Bafole, who sought to consider knowledge from 'other (foreign) lands' or when Fiona and Donald attempted to combine or find the middle ground between fractured systems. A third core value that propelled these headteachers to think and act comparatively is the sense of integrity that they conveyed through a set of other qualities as exemplified by Bafote:

You have to be a morally correct ...honest and transparent man, have moral integrity. (Bafote)

In taking risks, privileging inclusivity and acting with integrity, these headteachers were ultimately success-minded and in the case of the DRC headteachers. Success can be understood in different ways, for example, success was much more than pupils' outcomes that improve the standing of a given school but rather seen in th elong term for the greater good of the country:

Everything we do is geared towards boosting the competence of our children, provide and teach them information technology and life skills... so that they can come back as 'cadres' for this country. (Bafote)

\section{Conclusions and Recommendations}

This study has sought to compare leadership pathways, challenges and approaches of urban headteachers based in the DRC and England. The ultimate goal of the research was to understand how, in order to decolonise their schools from Western and local tyranies, DRC head teachers, in particular, were able to look across 
(compare) different leadership frameworks and develop a (diverse) context specific approach to school leadership. Using a narrative approach within a broader comparative theoretical framework, the study has not only identified similar and different thematic stories of (leadership pathways, challenges and leadership approaches) actions, it has also enable the development of an empirically-based comparative theory of context. The empirically-based leadership theory of context emerging from the study anchors comparative leadership approach on making sense of the ontological scope to which a leader would respond by going beyond his or her personal and professional selves and deploy his/her 'gospel according to the head teacher' metaphor comparative self fuelled by the set of values identified here. Navigating through these dynamics, it is argued, enabled (RDC) school leaders to decolonise theory, practice and policy by comparatively authoring their own brand of leadership for a specific time and space whether or not that their leadership behaviours are similar or different to pre-existent local or global leadership approaches.

Figure 1.

Comparative Leadership Framework

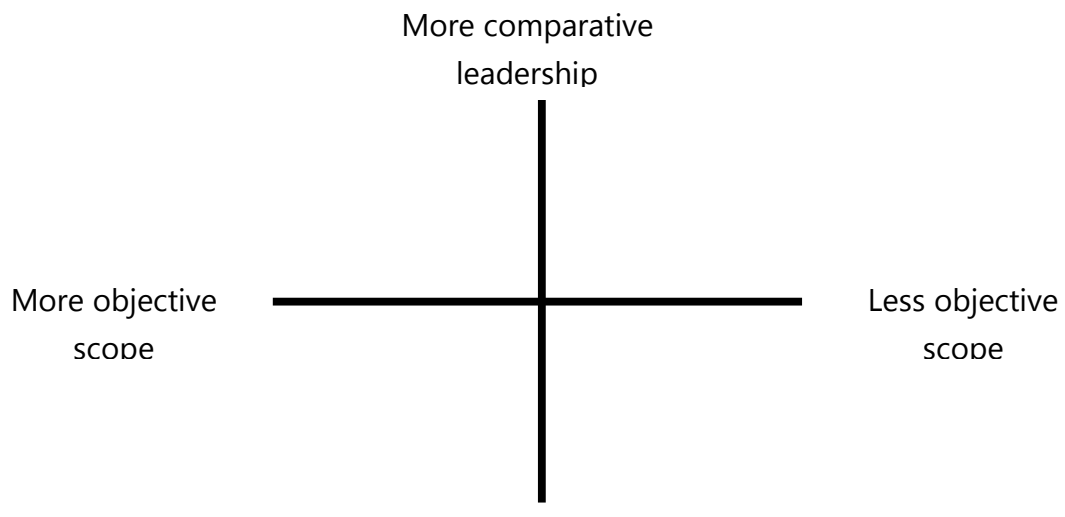


Figure 1 offers a visual illustration of the above cross-case discussion which shows that in an either more objective or subjective scope, school leaders can, as it was possible for both sets of headteachers, be more comparative rather than less comparative. More studies with bigger sample sizes are needed to not only reaffirm or not claims made here but also explore how school leaders act less comparatively in both objective scope and subjective scope. In the case of headteachers in this study, however, the comparative case could not be overstated. While recognising their different pathways, challenges to school leadership, they shared a common sentiment to be eclectic and comparative that delivered an underpinning theoretical theory of context(s).

It is posited that the diverse contexts that permeates into schools bring various ontologies, epistemologies, cultures, beliefs and assumptions that configure scope as either objective or subjective. While it is possible for headteachers to keep working within the bounds of a strictly objective or subjective scope and less comparative approach, these headteachers responded to their contrasting scopes by being more comparative. Whether the scope was more objective or not, the metaphor 'it's the gospel according to the head teacher' set the scene for identifying these headteachers' agentic responses which varied from literal through institutional to comparative interpretations. Headteachers can analyse the extent to which the literal and professional dispositions enable or hinder them to think and act locally and globally. However, in order to make comparartive leap, headteachers in this study drew from the core values of risk-taking (through circumvention, being creative...), inclusivity, integrity and success-mindedness that they applied in their respective objective and subjective contextual scopes. 


\section{References}

Bold, C. (2012). Using narrative in research. London: Sage.

Beugré, C. D., \& Offodile, O. F. (2001). Managing for oganisational effectiveness in Sub-Saharan Africa: A culture-fit model. International Journal of Human Resource Management, 12(4), 535550.

Beugré, C. D. (1998). La motivation au travail des cadres Africains [Work motivation of African managers]. Paris: Les Editions L'Harmettan.

Blunt, P., \& Jones, M. L. (1997). Exploring the limits of Western leadership theory in East Asia and Africa. Personnel Review, 26, 6-23.

Brock, C., \& Alexiadou, N. (2013). Education around the world: A comparative introduction. London: Bloomsbury.

Bush, T. (2011). Theories of educational leadership and management, $\left(4^{\text {th }}\right.$ ed.). London: Sage.

Bruce-Golding, J. (2019). Career trajectories of deputy and assistant headteachers and their perceptions of secondary headship. Journal of Education, 199(2), 59-68.

Bush, T. (2013). Preparing headship in England: Professional certification, not academic learning. Educational Management, Administration and Leadership, 41(4), 453-465.

Bush, T., \& Glover, D. (2014). School leadership models: What do we know? School leadership E Management, 34(5), 553-557.

Bush, T., \& Glover, D. (2016). School leadership in West Africa: Findings from a systematic literature review. Africa Education Review, 13(3-4), 80-102. 
Chapman, J. D. (2005). Recruitment, retention, and development of school principals. (Rapport): UNESCO.

Collard, J. (2007). Constructing theory for leadership in intercultural contexts. Journal of Educational Administration, 45(6), 740-755.

Day, C., Sammons, P., Leithwood, K., Hopkins, D., Gu, Q., Brown, E., \& Ahtaridou, E. (2011). Successful school leadership: Linking with learning and achievement. London: Sage.

De Angelis, M., Griffiths, D., Joshee, R., Portelli, J. P., Ryan, J., \& Zaretsky, L. (2007). Talking about social justice and leadership in a context of accountability. Journal of Educational Administration and Foundation, 18(1/2), 24-51.

De Herdt, T., Titeca, K., \& Wagemakers, I. (2012). Make schools, not war? Donors' rewriting of the social contract in the DRC. Development Policy Review, 30(6), 681-701.

Dimmock, C. (2012). Leadership, capacity building and school improvement: Concepts, themes and impact. London: Routledge.

Dimmock, C., \& Walker, A. (2000). Developing comparative and international educational leadership and management: A cross-cultural model. School Leadership and Management, 20(2), $143-160$.

Eacott, S. (2013). Towards a theory of school leadership practice: a Bourdieusian perspective. Journal of Educational Administration and History, 45(2), 174-188.

Eacott, S. (2015). Educational leadership relationally: A theory and methodology for educational leadership, management and administration. Springer. 
Elonga Mboyo, J. P. (2018). Framing ethical isomorphs in educational leadership: a sociological approach. International Journal of Leadership in Education, 21(1), 122-133.

Elonga Mboyo, J. P. (2019). Reimagining Ubuntu in schools: A perspective from two primary school leaders in the Democratic Republic of Congo. Educational Management Administration $\mathcal{E}$ Leadership, 47(2), 206-223.

Epitropaki, O., Kark, R., Mainemelis, C. \& Lord, R. (2017). Leadership and followership identity processes: A multilevel review. Leadership Quarterly, 28, 104-129.

Glatter, R. (2012). Persistent preoccupations: The rise and rise of school autonomy and accountability in England. Educational Management, Administration \& Leadership, 40(5), 559-575.

Goodson, I. (2013). Developing narrative theory: Life histories and personal representations. London: Routledge.

Gunter, M. H., \& Fitzgerald, T. (2008). The future of leadership research? School Leadership \& Management: Formerly School Organisation, 28(3), 261-279.

Hallinger, P., \& Heck, H. R. (2002). What do you call people with vision? The role of vision, mission and goals in school leadership and improvement. In K. Leithwood \& P. Hallinger (Eds.), Second International Handbook of Educational Leadership and Administration (9-40). London: Kluwer Academic publishers.

Hallinger, P., \& Heck, H. R. (1996). The principal's role in school effectiveness: An assessment of methodological progress. In K. Leithwood, J. Chapman, D. Coron, P. Hallinger \& A. Hart (Eds.), International handbook of educational leadership and 
administration Dordrecht (pp. 723-783). Netherlands: Kluwer Academic Publishers.

Hallinger, P. (2003). Leading educational change: Reflections on the practice of instructional and transformational leadership. Cambridge Journal of Education, 33(3), 329-352.

Hammersley, F. L. (2015). Value(s)-driven decision making: The ethics work of English head teachers within discourses of constraint. Educational Management, Administration \& Leadership, 43(2), 198213.

Hargreaves, A. (2003). Teaching in the knowledge society: Education in the age of insecurity. Maidenhead: Open University Press.

Heck, R. H., \& Hallinger, P. (2005). The study of educational leadership and management: Where does the field stand today? Educational Management Administration \& Leadership, 33, 229244.

Higham, R., Earley, P., Coldwell, M., Stevens, A., \& Brown, C. (2015). New pathways into headship? National College for Teaching and Leadership.

Hooge, E., Burns T., \& Wilkoszewski, H. (2012). Looking beyond the numbers: Stakeholders and multiple school accountability, OECD Education Working Papers, No 85. OECD Publishing.

Jha, M. M. (2007). Barriers to student access and success: Is inclusive education an answer? In K. J. Verma, R. C. Bagley \& M. M. Jha, (Eds.), In International Perspectives on Educational Diversity and Inclusion: Studies from America, Europe and India (pp.33-44). London: Routledge.

Jones, M. L., Blunt, P., \& Sharma, K. C. (1996). Managerial perceptions of leadership and management in an African public service 
organisation. Public Administration and Development, 16, 455467.

Kambanda, S. (2013). The role of high school principals in leading and managing school cultures: A case study of Huye district in Rwanda. Unpublished $\mathrm{PhD}$ thesis, Johannesburg, University of the Witwatersrand.

Kaparou, M. (2013). Instructional leadership in secondary high performing schools within two contrasting educational systems: case studies in English and Greek schools. Unpublished Ph.D. thesis, Coventry, University of Warwick.

Kaparou, M., \& Bush, T. (2016). Instructional leadership in Greek and English outstanding schools. International Journal of Educational Management, 30(6), 894-912.

Kiggundu, M. N., Jorgensen, J. J., \& Hafsi, T. (1983). Administrative theory and practice in developing countries: a synthesis. Administrative Science Quarterly, 28, 66-84.

Leithwood, K., Begley, P., \& Cousins, B. (1994). Developing expert leadership for future schools. London: Falmer Press.

Leithwood, K., Harris, A., \& Hopkins, D. (2008). Seven strong claims about successful school leadership. School Leadership and Management, 28(1), 27-42.

Lumby, J., \& Heystek, J. (2011). Leadership identity in ethnically diverse schools in South Africa and England. Educational Management, Administration \& Leadership, 40(1), 4-20.

MacBeath, J. (2011). No lack of principles: Leadership development in England and Scotland. School Leadership and Management, 31(2), 105-121. 
Maringe, F., \& Moletsane, R. (2015). Leading schools in circumstances of multiple deprivation in South Africa: Mapping some conceptual, contextual and research dimensions. Educational Management, Administration E Leadership, 43(3), 347-362.

Michalak, J. (2012). Inclusive school leadership in challenging urban communities: a comparative study. Solsko Polje, 23(1/2), 183.

Mokonzi, G. (2010). DRC: Effective delivery of public services in the education sector. Johannesburg: Open Society Institute for Southern Africa.

Morgan, G. (2006). Images of organisation. London: Sage.

Northouse, G. P. (2016). Leadership: Theory and practice (7 $7^{\text {th }}$ ed.). London: Sage.

Reed, L. (2008). An expansion of a scholar's social justice perspective: A meeting at the crossroads. Journal of School Leadership, 18(2), 200-223.

Reed, L., \& Swaminathan, R. (2015). An urban school leader's approach to school improvement: Towards contextually responsive leadership. Urban Education, 51(9), 1096-1125.

Ribbins, P., \& Gunter, H. (2002). Mapping leadership studies in education: Towards a typology of knowledge domains. Education Management \& Administration, 30(4), 359-385.

Riessman, K. C. (2008). Narrative methods for the human sciences. London: Sage.

Sackey, L., \& Mitchell, C. (2002). Postmodern expressions of educational leadership. In K. Leithwood \& P. Hallinger (Eds.), Second International Handbook of Educational Leadership and Administration (pp.881-913). Dordrecht: Kluwer Academic Publishers. 
Schuttloffel, M. J. (2013). Contemplative leadership practice: The influences of character on catholic school leadership. Journal of Catholic Education, 17(1), 81-103.

Schweisfurth, M. (2001). Gleaning meaning from case studies in international comparison: Teachers' experiences of reform in Russia and South Africa. In K. Watson (Ed.), Doing Comparative Research: Issues and Problems (pp.211-223). Oxford: Symposium Books.

Shapiro, D., \& Tambashe, B. O. (2001). Gender, poverty, family structure, and investments in children's education in Kinshasa, Congo. Economics of Education Review, 20, 359-375.

Simkins, T. (2003). Reform, accountability and strategic choice in education, In Preedy et al (Eds.). Strategic Leadership and Educational Improvement. London: Paul Chapman Publishing.

Southworth, G. (2003). Learning centred-leadership in schools. In L. Moos (Ed.), Educational Leadership (pp.33-52). Copenhagen: Danish University of Educational Press.

Thomson, P. (2010). Headteacher autonomy: A sketch of a Bourdieuian field analysis of position and practice. Critical Studies in Education, 51(1), 5-20.

Townsend, T. (2010). Educating school leaders to think and act both locally and globally. International Journal of Leadership in Education, 13(3), 335-348.

UNESCO. (2012-UIS). Adult and youth literacy, 1990-2015: Analysis of Data for 41 Selected Countries.

Vandermause, R., Leiker, B. C., \& Fritz, R. (2014). Research education: Findings of a study of teaching-learning research using 
multiple analytical perspectives. Journal of Nursing Education, 53(12), 673-677.

Wang, F. (2018). Leadership as a subversive activity: Principals' perceptions. International Journal of Leadership in Education, 21(5), 531-544.

Zame, M. Y., Hope, W. C., \& Respress, T. (2008). Educational reform in Ghana: the leadership challenge. International Journal of Educational management, 22(2), 115-128.

Zoogah, B. D., \& Nkomo, S. (2013). Management research in Africa, past, present and future. In R. T. Lituchy, B. J. Punnett, \& B. B. Puplampu (Eds.), Management in Africa, Macro and Micro Perspectives (pp.9-31). London: Routledge.

\footnotetext{
About the author:

Jean Pierre Elonga Mboyo is Senior Lecturer at Teesside University. He teaches an undergraduate and postgraduate courses and researches educational leadership.

Email: jp.elonga@tees.ac.uk

Twitter: @jpelonga
} 